\title{
Smartphone-Based Remote Health Monitoring-Implications for Healthcare Delivery in Patients with Cirrhosis
}

\author{
Jordan Sack, $M D^{1,2}$ and Nikroo Hashemi, MD MPH',2
}

'Division of Gastroenterology, Hepatology, and Endoscopy, Brigham and Women's Hospital, Boston, MA, USA; ${ }^{2}$ Harvard Medical School, Boston, MA, USA.

J Gen Intern Med 34(12):2726-7

DOI: $10.1007 / \mathrm{s} 11606-019-05046-y$

(c) Society of General Internal Medicine 2019

\section{INTRODUCTION}

Cirrhosis is a leading cause of morbidity, hospitalization, and readmissions in the United States, which drive healthcare costs and increase mortality. ${ }^{1,} 2$ Healthcare delivery for these patients is often fragmented and inadequate. $^{3}$ As patients with cirrhosis may be hospitalized with complications that have premonitory warning signs, smartphone-based remote health monitoring may allow for earlier detection of physiological abnormalities to reduce hospitalizations and to improve long-term outcomes. ${ }^{4-6}$ Our prospective study aims to investigate the prevalence of smartphone use among patients with decompensated cirrhosis and how they relate to clinical, demographic, and social characteristics.

\section{METHODS}

We conducted a prospective multicenter study of English-speaking patients with decompensated cirrhosis aged $\geq 18$ years who received inpatient or ambulatory liver care at one of three urban academic centers (two are tertiary care and one has a liver transplant program). Screening was performed over a 16-month period that ended January 2019 by weekly review of all provider lists. Patients were eligible if they had hepatic encephalopathy actively being treated, refractory ascites requiring large volume paracenteses, spontaneous bacterial peritonitis, or history of variceal bleeding within the previous 3 months. Patients were excluded if they were actively using alcohol or drugs, not fluent in English, or on hospice. Eligible patients were contacted in-person or by telephone up to three times within 1 week prior to their scheduled clinic visit regarding smartphone usership, defined as using the full functionality of a smartphone. Patients were classified as Android, iPhone, or non-smartphone users. Data was collected on age, sex, race, marital status, long-term partner relationship,

Published online May 14, 2019 education, employment, disability, cirrhosis etiology, hepatic encephalopathy actively being treated, liver transplant listing status, patient interest in smartphone-based remote health monitoring applications, distance from study centers, and estimated household income based on household zip code using data from the United States Census Bureau and the 2017 American Community Survey 5 -year estimates. We performed analyses with chisquare, $t$ test, and linear regression using SAS 9.4 (SAS Institute, Cary, NC). Institutional Review Board approval was obtained.

\section{RESULTS}

Three hundred forty-one patients were identified, of whom $281(82.4 \%)$ participated. Two hundred one $(71.5 \%)$ patients had a smartphone, defined as using the full functionality of a smartphone. Of the 80 patients categorized as smartphone non-users, 68 did not possess a smartphone. One hundred eleven patients had an iPhone and 90 had an Android. Reasons for lack of participation included patient unreachability $(n=$ $42)$, death during recruitment period $(n=10)$, study refusal $(n=6)$, and liver transplantation during recruitment period $(n=2)$.

Patients with smartphones tended to be younger, married, employed, and reside in higher income zip codes (Table 1). On multivariate analysis correcting for sex, marital status, hepatic encephalopathy, liver transplant listing, not working, disability, and interest in smartphone-based remote health monitoring, only age $\geq 55$ years (OR 8.79) and alcohol etiology of cirrhosis (OR 5.21) were independently associated with not having a smartphone. Characteristics of Android and iPhone users are described in Table 2.

Patient interest in smartphone-based remote health monitoring applications did not differ between smartphone users and non-users (Table 1). When all study patients were analyzed regardless of smartphone status, there was no statistically significant difference in hepatic encephalopathy, alcohol etiology of cirrhosis, or liver transplant listing.

There was a high prevalence of hepatic encephalopathy and alcohol etiology, but there were no statistically significant 
Table 1 Sociodemographic Data of Decompensated Cirrhosis Patients by Smartphone Status

\begin{tabular}{|c|c|c|c|}
\hline & $\begin{array}{l}\text { Smartphone, } \\
N=201\end{array}$ & $\begin{array}{l}\text { Non-smartphone, } \\
N=\mathbf{8 0}\end{array}$ & $P$ value \\
\hline Mean age \pm SD & $57.7 \pm 9.3$ & $62.0 \pm 8.3$ & 0.0004 \\
\hline Male, $\%$ & 62.2 & 56.3 & 0.417 \\
\hline Caucasian, \% & 89.1 & 91.3 & 0.826 \\
\hline Married, \% & 65.7 & 51.3 & 0.029 \\
\hline $\begin{array}{l}\text { Long term partner } \\
\text { relationship, } \%\end{array}$ & 69.2 & 57.5 & 0.069 \\
\hline $\begin{array}{l}\text { High school diploma } \\
\text { or higher, } \%\end{array}$ & $\begin{array}{l}96.8 \\
(n=90 / 93)\end{array}$ & $\begin{array}{l}81.8 \\
(n=27 / 33)\end{array}$ & 0.010 \\
\hline Not working, $\%$ & 65.2 & 86.3 & 0.007 \\
\hline Disabled, \% & 30.1 & 46.3 & 0.067 \\
\hline Alcohol etiology, \% & 56.2 & 65.0 & 0.183 \\
\hline $\begin{array}{l}\text { Hepatic } \\
\text { encephalopathy, \% }\end{array}$ & 76.7 & 81.3 & 0.430 \\
\hline $\begin{array}{l}\text { Liver transplant } \\
\text { listed, } \%\end{array}$ & 33.8 & 27.5 & 0.653 \\
\hline $\begin{array}{l}\text { Mean distance from } \\
\text { center } \pm \text { SD (miles) }\end{array}$ & $57.1 \pm 62.8$ & $49.8 \pm 69.2$ & 0.395 \\
\hline $\begin{array}{l}\text { Mean household } \\
\text { income } \pm \text { SD (USD) }\end{array}$ & $100,599 \pm 35,899$ & $91,776 \pm 27,564$ & 0.028 \\
\hline $\begin{array}{l}\text { Interested in remote } \\
\text { health app, } \%\end{array}$ & 70.5 & 77.6 & 0.367 \\
\hline
\end{tabular}

associations between these and being married, having a longterm partner relationship, being on disability, not working, or having at least a high school level of education.

\section{DISCUSSION}

Our study demonstrated that smartphone-based remote monitoring may be practical for patients with decompensated cirrhosis. We found a high prevalence of smartphone use-defined as using the full functionality

Table 2 Sociodemographic Data of Decompensated Cirrhosis Patients by Smartphone Type

\begin{tabular}{llll}
\hline \hline & $\begin{array}{l}\text { iPhone, } \\
\boldsymbol{N}=\mathbf{1 1 1}\end{array}$ & $\begin{array}{l}\text { Android, } \\
\boldsymbol{N}=\mathbf{9 0}\end{array}$ & $\boldsymbol{P}$ value \\
\hline Mean age \pm SD & $57.9 \pm 9.9$ & $57.4 \pm 8.5$ & 0.731 \\
Male, \% & 55.9 & 70.0 & 0.042 \\
Caucasian, \% & 90.9 & 87.8 & 0.642 \\
Married, \% & 72.7 & 57.8 & 0.035 \\
Long term partner & 76.4 & 61.1 & 0.022 \\
relationship, \% & & & \\
High school diploma & 97.9 & 95.6 & 0.609 \\
$\quad$ or higher, \% & $(n=43 / 45)$ & $(n=47 / 48)$ & \\
Not working, \% & 74.2 & 81.3 & 0.356 \\
Disabled, \% & 23.4 & 40.0 & 0.055 \\
Alcohol etiology, \% & 52.3 & 61.1 & 0.253 \\
Hepatic encephalopathy, \% & 73.0 & 81.1 & 0.185 \\
Liver transplant listed, \% & 34.2 & 33.3 & 0.951 \\
Mean distance from & $47.2 \pm 49.5$ & $69.3 \pm 74.6$ & 0.017 \\
$\quad$ center \pm SD (miles) & & & \\
Mean household & $108,448 \pm$ & $90,809 \pm$ & 0.0005 \\
income \pm SD (USD) & 36,333 & 33,007 & \\
Interested in remote & 72.6 & 68.7 & 0.603 \\
health app, \% & & & \\
\hline
\end{tabular}

of a smartphone - among English-speaking patients with decompensated cirrhosis who received hepatology care at our academic centers. Smartphone users tended to be younger, married, employed, residing in zip codes of higher incomes, and to have a non-alcoholic etiology of cirrhosis. The vast majority of patients, regardless of hepatic encephalopathy or smartphone usership, were interested in smartphone-based remote health monitoring applications. Hepatic encephalopathy was common among smartphone users and half of our patients did not have a spouse or long-term partner. These clinical and sociodemographic observations may help to inform future development of remote health applications that are targeted for patients with decompensated cirrhosis with the goal of improving liver-related outcomes.

Acknowledgments: An interim analysis was accepted for poster presentation at the annual Digestive Disease Week conference, May 2019.

Corresponding Author: Nikroo Hashemi, MD MPH; Harvard Medical School, Boston, MA, USA (e-mail: nhashemi@bwh.harvard.edu).

Author Contributions JS: study concept and design, acquisition of data, interpretation of data, manuscript writing.

NH: study concept and design, interpretation of data, manuscript writing.

Funding This study was financially supported by the American Association for the Study of Liver Disease Innovation Fund.

\section{Compliance with Ethical Standards:}

Conflict of Interest: The authors declare that they do not have a conflict of interest.

\section{REFERENCES}

1. Bajaj JS, Reddy KR, Tandon $\mathbf{P}$, et al. The 3-month readmission rate remains unacceptably high in a large North American cohort of patients with cirrhosis Hepatology. 2016; 64(1):200-208.

2. Tapper EB, Halbert B, Mellinger $\mathbf{J}$ Rates of and reasons for hospital readmissions in patients with cirrhosis: a multistate population-based cohort study Clin Gastroenterol Hepatol. 2016; 14(8): 1181-1888.

3. Seraj SM, Campbell EJ, Argyropoulos SK, et al. Hospital readmissions in decompensated cirrhotics: factors pointing toward a prevention strategy. World J Gastroenterol. 2017;23(37):6868-6876.

4. Singal A, Rahimi R, Clark C, et al. An automated model using electronic medical record data identified patients with cirrhosis at high risk for readmission Clin Gastroenterol Hepatol. 2013; 11(10): 1335-1341.

5. Serper M, Volk ML. Current and future applications of telemedicine to optimize the delivery of care in chronic liver disease Clin Gastroenterol Hepatol. 2018;16(2):157-161.

6. Ganapathy D, Acharya C, Lachar J, et al. The patient buddy app can potentially prevent hepatic encephalopathy-related admissions Liver Int. 2017; 37(12):1843-1851.

Publisher's Note Springer Nature remains neutral with regard to jurisdictional claims in published maps and institutional affiliations. 